\title{
PEMANFAATAN LIMBAH CANGKANG KERANG HIJAU DENGAN VARIASI SUHU PEMBAKARAN SEBAGAI BAHAN PENGGANTI SEBAGIAN SEMEN PADA PEMBUATAN BETON
}

\author{
Julia Widia Nika', Anisah², Sittati Musalamah ${ }^{3}$ \\ 1,2,3 Pendidikan Teknik Bangunan, FT, UNJ \\ Email: Anisah_mt@unj.ac.id
}

\begin{abstract}
ABSTRAK
Penelitian ini bertujuan untuk memanfaatkan limbah cangkang kerang hijau sebagai bahan pengganti sebagian semen dengan mencari suhu pembakaran cangkang kerang hijau terbaik yang seharusnya digunakan agar mendapatkan kandungan kimia pada abu cangkang kerang agar menyerupai kandungan kimia pada semen secara optimal. Penelitian ini mengganti $10 \%$ dari berat semen total dengan abu cangkang kerang yang telah dibakar dengan suhu $700^{\circ} \mathrm{C}, 800^{\circ} \mathrm{C}$ dan $900^{\circ} \mathrm{C}$ serta beton normal sebagai kontrol. Kuat tekan rencana beton adalah $20 \mathrm{MPa}$. Campuran beton yang digunakan 1:2:3. Hasil penelitian ini menunjukkan bahwa kuat tekan beton yang diperoleh dengan mengganti $10 \%$ berat semen dengan abu cangkang kerang hijau dengan suhu pembakaran $700^{\circ} \mathrm{C}, 800^{\circ} \mathrm{C}$ dan $900^{\circ} \mathrm{C}$ berturut turut adalah 20,53 MPa; 16,76MP dan 19,74 MPa, sedangkan beton kontrol memiliki kuat tekan 20,18MPa. Kuat tekan maksimal diperoleh pada beton abu cangkang kerang dengan suhu pembakaran $700^{\circ} \mathrm{C}$. Pada beton abu cangkang kerang hijau dengan suhu pembakaran di atas $700^{\circ} \mathrm{C}$ mengalami penuruan kuat tekan dan tidak dapat memenuhi kuat tekan rencana.
\end{abstract}

Kata Kunci: Beton, Kerang Hijau, Suhu Pembakaran.

\begin{abstract}
This research aims to utilize green mussel shell waste as a partial replacement for cement by establishing the best temperature that should be used to obtain the chemical substance if the sehell ashes to optimize the chemical substance for replacement of cement. This research replaces $10 \%$ of total weight cement with shell ash which has been combusted with a temperature of $700^{\circ} \mathrm{C}, 800^{\circ} \mathrm{C}$ and $900{ }^{\circ} \mathrm{C}$ and control concrete. The compressive strength of the concrete plan is $20 \mathrm{MPa}$. Concrete mix design is 1:2:3.

The results of this study indicate with subtitutes $10 \%$ semen with green shell ash with temperature $700{ }^{\circ} \mathrm{C}, 800^{\circ}$ $\mathrm{C}$ and $900^{\circ} \mathrm{C}$ is 20,53MPa; 16,76 MPa and 19,74 MPa and for control concrete has compressive strength 20,18 MPa. The maximum concrete compressive strength was obtained on the concrete of green shell ash with a combustion temperature of $700{ }^{\circ} \mathrm{C}$ which is $20.53 \mathrm{MPa}$. In the concrete the green shells ash with a burning temperature above $700^{\circ} \mathrm{C}$ experience a decrease in compressive strength and cannot meet the compressive strength of the plan.
\end{abstract}

Keywords: Concrete, Green Shell, Temperature Combustion 


\section{PENDAHULUAN}

Kebutuhan beton di Indonesia dalam pembangunan infrastruktur dan perumahan semakin meningkat. Meningkatnya kebutuhan beton untuk pembangunan infrastruktur menimbulkan banyaknya inovasi tentang pemanfaatan material pengganti atau pun bahan tambah pada beton(Martati, 2012). Pada umumnya, bahan yang digunakan sebagai bahan pengganti maupun bahan tambah pada beton merupakan limbah yang terdapat pada lingkungan sekitar. Salah satu limbah organik yang menjadi permasalahan di kota - kota besar di Indonesia adalah limbah kerang (Asto, 2015). Limbah kerang yang terdapat di Muara Kali Cakung Drain, Jakarta Utara, sudah menumpuk bahkan sudah berbentuk seperti tanggul yang menutupi setengah dari lebar Muara Kali Cakung Drain. (Sutanto, 2014,https://www.merdeka.com/jakarta/sa mpah-kulit-kerang-numpuk-di-muaracakung-drain-seperti-tanggul.html).

Abrori (2015) mendapatkan kuat tekan beton maksimum dengan mengganti $10 \%$ berat total semen dengan abu cangkang kerang hijau. Maulana (2014) mendapatkan hasil kuat tekan pada batako bertulang dengan mengganti $7,5 \%$ berat total semen dengan abu cangkang kerang hijau. Berdasarkan penelitian relevan, ditetapkan untuk mengganti $10 \%$ berat total semen dengan cangkang kerang hijau. Penggunaan cangkang kerang hijau yang maksimum diharapkan dapat lebih banyak mengurangi limbah cangkang kerang yang terdapat di lingkungan.

Namun, untuk menjadikan cangkang kerang sebagai bahan substitusi semen harus melalui beberapa proses, di antaranya adalah proses pembakaran. Proses pembakaran cangkang kerang bertujuan untuk mengurai komposisi senyawa kimia yang terdapat di dalam cangkang kerang agar lebih mudah dimaksimalkan pemanfaatannya. Berdasarkan penelitian yang dilakukan oleh Abrori (2015) dan
Maulana (2014), waktu pembakaran cangkang kerang dilakukan selama 4 jam setelah ketercapaian suhu yang ditentukan.

Pada penelitian sebelumnya, suhu pembakaran cangkang kerang ditetapkan berdasarkan referensi penelitian terdahulu. Berdasarkan penelitian yang dilakukan oleh Abrori (2015) dan (Arif dkk, 2013) suhu yang digunakan pada proses pembakaran adalah $800^{\circ} \mathrm{C}$.

Penelitian yang dilakukan oleh Maulana (2014) menggunakan suhu pembakaran $670^{\circ} \mathrm{C}$. Syafpoetri (2013) menggunakan suhu $700^{\circ} \mathrm{C}$ pada proses pembakaran. Sehingga belum didapatkan batas pada suhu berapa pembakaran cangkang kerang akan menghasilkan kandungan kapur secara optimum.

Berdasarkan kondisi tersebut, perlu dilakukan sebuah penelitian mengenai pemanfaatan limbah kerang dengan fokus pada suhu pembakaran dalam proses pengabuan cangkang kerang hijau yang bertujuan untuk mencari suhu yang tepat agar kandungan kimia yang sama dengan kandungan kimia pada semen yang terdapat pada cangkang kerang hijau dapat keluar secara optimum sehingga dapat menambah kuat tekan beton.

Dari latar belakang masalah, dapat didentifikasi beberapa masalah, yaitu:

1. Apakah cangkang kerang hijau (Perna viridis) yang diperoleh dari kawasan Muara Karang dapat digunakan sebagai bahan pengganti sebagian semen pada campuran beton normal?

2. Berapa derajat celsius suhu pembakaran yang dibutuhkan agar cangkang kerang dapat mengeluarkan kandungan komposisi kimia yang menyerupai semen secara optimum?

3. Apakah terjadi perubahan kuat tekan pada beton setelah diberikan campuran abu kerang hijau yang memiliki kandungan silika yang beragam?

4. Pada suhu pembakaran kulit kerang hijau berapa derajat akan menghasilkan kuat tekan beton optimal? 
Pembatasan Masalah

Penelitian ini memerlukan adanya pembatasan masalah, di antaranya adalah :

1. Pasir yang digunakan adalah pasir Cirebon.

2. Semen yang digunakan adalah semen Portland tipe 1.

3. Kerikil yang digunakan adalah pasir Tangerang.

4. Cangkang kerang yang digunakan adalah cangkang kerang hijau (Perna Viridis) yang didapatkan di kawasan Muara Karang, Jakarta Utara.

5. Suhu yang digunakan untuk pembakaran cangkang kerang hijau adalah $700^{\circ} \mathrm{C}, 800^{\circ} \mathrm{C}$ dan $900^{\circ} \mathrm{C}$.

6. Waktu yang digunakan pada proses pembakaran cangkang kerang adalah 4 jam dari waktu pencapaian target suhu.

7. Persentase abu cangkang kerang dipakai sebanyak $10 \%$ dari total berat semen.

8. Kuat tekan rencana adalah $20 \mathrm{MPa}$ dan f.a.s yang digunakan sebesar 0,5 .

9. Benda uji beton yang digunakan berbentuk silinder diameter $15 \mathrm{~cm}$ dan tinggi $30 \mathrm{~cm}$ sebanyak 3 buah untuk masing - masing variabel.

10. Pembuatan Mix Design berdasarkan ASTM C33-02a.

11. Pembuatan dan perawatan benda uji beton berdasarkan SNI 03-48101998.

12. Prosedur pengujian kuat tekan beton berdasarkan SNI 03-64292000 tentang Metode Pengujian Kuat Tekan Beton Silinder Dengan Cetakan Silinder di Dalam Tempat Cetakan.

13. Pengujian beton dilakukan pada saat beton umur 28 hari.
Berdasarkan identifikasi masalah serta pembatasan masalah di atas, dapat diketahui rumusan masalah, yaitu:

"Bagaimanakah pengaruh penggunaan abu cangkang kerang hasil pembakaran dengan variasi suhu $700^{\circ} \mathrm{C}, 800^{\circ} \mathrm{C}$ dan $900^{\circ} \mathrm{C}$ sebagai pengganti sebagian semen pada pembuatan beton terhadap kuat tekan yang dihasilkan?".

Tujuan dari penelitian ini adalah untuk mencari suhu terbaik yang seharusnya digunakan pada saat proses pembakaran cangkang kerang agar mendapatkan kandungan kimia pada abu cangkang kerang agar menyerupai kandungan kimia pada semen secara optimal.

Manfaat Penelitian

1. Mengurangi limbah kulit kerang hijau yang tidak terpakai.

2. Memperoleh variasi bahan pengganti semen.

3. Menjadi acuan dalam menentukan suhu yang tepat pada proses pembakaran yang diaplikasikan pada mata pelajaran praktek uji bahan.

\section{METODE PENELITIAN}

Metode penelitian yang akan dilakukan dalam penelitian ini adalah metode eksperimen. Benda uji yang akan digunakan merupakan beton berbentuk silinder dengan diameter $15 \mathrm{~cm}$ dan tinggi $30 \mathrm{~cm}$ yang dibuat dengan mengganti $10 \%$ semen dari semen total dengan abu cangkang yang kerang yang dibakar dengan suhu $700^{\circ} \mathrm{C}, 800^{\circ} \mathrm{C}$ dan $900^{\circ} \mathrm{C}$.

Perlakuan penelitian meliputi tahap persiapan, tahap pemeriksaan bahan, tahap perencanaan proporsi campuran, tahap pengadukan, tahap pengujian slump, tahap pembuatan benda uji, tahap perawatan benda uji, serta tahap pengujian kuat tekan benda uji. Suhu Pembakaran Cangkang Kerang Pengabuan cangkang kerang dilakukan dengan melalui beberapa proses yaitu pencucianpengeringan,penghancuran serta pembakaran (Syafpoetri, 2013). Tujuan pengabuan cangkang kerang hijau 
adalah agar unsur yang terdapat pada cangkang kerang dapat meningkat

Langkah - langkahnya dimulai dengan pencucian cangkang kerang hijau yang diambil dari tempat pengupasan kerang lalu dijemur di bawah sinar matahari dan dihancurkan dengan mesin disk mill. Cangkang yang telah dihancurkan kemudian di oven. Hasilnya berupa abu kulit kerang hijau yang bersifat "Pozzolan". (Abrori, 2015).

Pada beberapa bahan organik lainnya, faktor suhu pembakaran sangat penting dalam mengeluarkan kandungan kimia yang terdapat pada bahan organik. Meningkatnya suhu pembakaran dapat menghilangkan karbon dan meningkatkan kandungan kimia yang terdapat dalam bahan - bahan organik. Ummah dkk (2010) meneliti tentang suhu pembakaran pada abu sekam padi. Jumlah kualitatif $\mathrm{SiO} 2$ dari abu sekam padi hasil pengabuan pada suhu pengabuan $600^{\circ} \mathrm{C}$, $700^{\circ} \mathrm{C}$ dan $800^{\circ} \mathrm{C}$ meningkat. Seiring kenaikan suhu, karbon yang terdapat pada abu sekam padi semakin menghilang. Hal ini karena kenaikan suhu pengabuan senyawa karbon dan gugus - $\mathrm{OH}$ menguap membentuk senyawa karbondioksida dan air pada proses pengabuan.

\section{PEMBAHASAN}

Material yang akan digunakan dalam penelitian di uji berdasarkan SNI 03-19681990 tentang Metode Pengujian Analisis Saringan Agregat Halus dan Kasar. Material yang akan dilakukan uji pendahuluan adalah agregat kasar dan halus. Pengujian bahan dilakukan di Labotarium Uji Bahan Universitas Negeri Jakarta. Hasil dari uji pendahuluan terdapat pada Tabel 2.

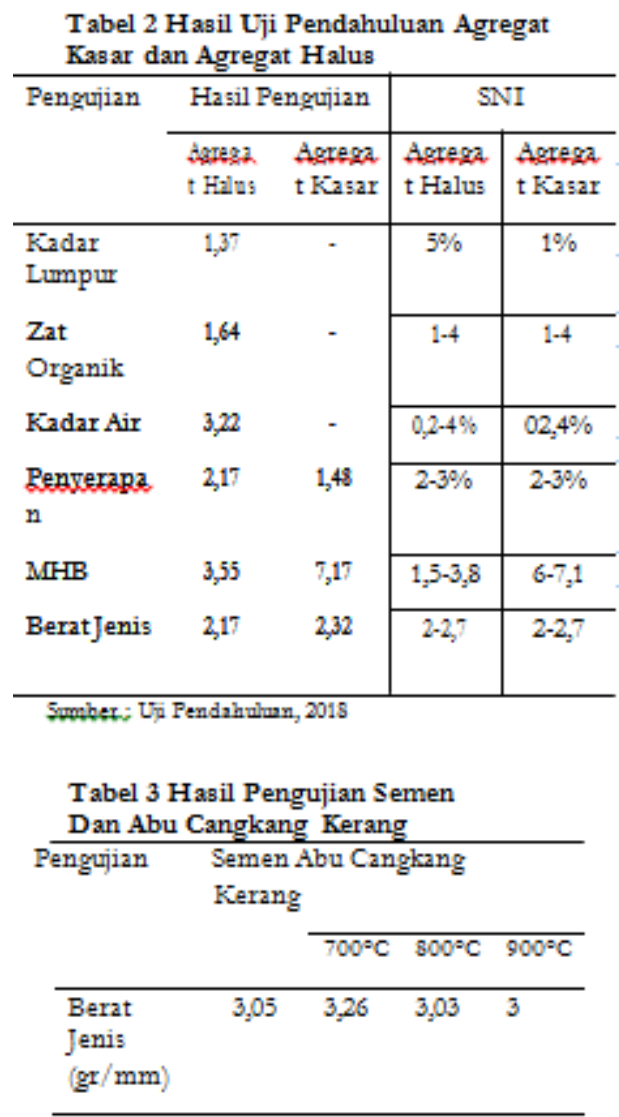

Berdasarkan Tabel 2 dan 3 mengenai uji pendahuluan terhadap bahan penyusun beton dapat diketahui bahwa bahan - bahan tersebut lolos uji Standar Nasional Indonesia (SNI).

Cangkang kerang hijau yang telah diproses menjadi abu dilakukan pengujian unsur senyawa dan berat jenis. Pengujian kandungan unsur senyawa pada cangkang kerang dilakukan di Lab Fire Universitas Negeri Jakarta. Hasil Uji kandungan senyawa pada abu cangkang kerang dapat dilihat pada Tabel 4.

\begin{tabular}{|c|c|c|c|}
\hline \multirow[t]{2}{*}{ Pengujian } & \multicolumn{3}{|c|}{ Hasil Uji } \\
\hline & $700^{\circ} \mathrm{C}$ & $800^{\circ} \mathrm{C}$ & $900^{\circ} \mathrm{C}$ \\
\hline $\begin{array}{l}\text { Berat } \\
\text { Jenis }\end{array}$ & & & \\
\hline $\mathrm{GaO}$ & 46,47 & 44,23 & 53,86 \\
\hline $\mathrm{Na}_{2} \mathrm{O}$ & 1,83 & 0,59 & 1,33 \\
\hline $\mathrm{CO} 2$ & 50,2 & 51,88 & 26,8 \\
\hline c & - & 3,29 & - \\
\hline $\mathrm{O} 2$ & 1,5 & - & 18,01 \\
\hline
\end{tabular}


Proses pengabuan cangkang kerang memiliki kendala pada bahan bakar oven. Pembakaran pada suhu $900^{\circ} \mathrm{C}$ harus dilakukan penggantian bahan bakar sehingga menyebabkan penurunan suhu serta membutuhkan waktu untuk mencapai kembali suhu $900^{\circ} \mathrm{C}$.

\section{Uji Slump}

Pengujian Slump untuk beton normal dan beton abu cangkang kerang hijau suhu pembakaran $700^{\circ} \mathrm{C}, 800^{\circ} \mathrm{C}$ dan $900^{\circ} \mathrm{C}$ dengan nilai slump rencana $12 \pm 2$ menghasilkan nilai Slump seperti pada Tabel 5.

\section{Tabel 5 Hasil Uji Slump}

\begin{tabular}{lcc}
\hline Benda Uji & \multicolumn{1}{c}{$\begin{array}{c}\text { Nilai } \\
\text { Slump } \\
(\mathrm{cm})\end{array}$} \\
& & \\
\hline $\begin{array}{l}\text { Beton Normal } \\
\text { Beton }\end{array}$ & 12 \\
$\begin{array}{l}\text { Cangkang } \\
\text { Kerang } 700^{\circ} \mathrm{C} \\
\text { Beton }\end{array}$ & \\
$\begin{array}{l}\text { Cangkang } \\
\text { Kerang } 800^{\circ} \mathrm{C} \\
\text { Beton }\end{array}$ & \\
Cangkang Abu \\
Kerang $900^{\circ} \mathrm{C}$ & \\
\hline
\end{tabular}

\section{Sumber : Data Uji Berat Isi, 2018}

Berdasarkan data hasil penelitian uji slump, penggunaan abu cangkang kerang hijau dengan suhu pembakaran $900^{\circ} \mathrm{C}$ sebagai bahan pengganti sebagian semen membuat nilai slump turun dan tidak dapat mencapai nilai slump rencana. Sedangkan pada penggunaan abu cangkang kerang dengan suhu $700^{\circ} \mathrm{C}$ dan suhu $900^{\circ} \mathrm{C}$ nilai slump kembali dapat memenuhi nilai rencana.

\section{Berat Isi Beton}

Benda uji yang telah direndam selama 28 hari diangkat dan dikeringkan, setelah itu dilakukan uji berat isi beton. Hasil pengujian berat isi beton terdapat pada Tabel 6.

Tabel 6 Hasil Berat Beton Umur 28 Hari

\begin{tabular}{|c|c|c|c|c|c|}
\hline \multirow{2}{*}{$\begin{array}{l}\mathrm{U} \\
\mathrm{mu} \\
\mathrm{r}\end{array}$} & \multirow{2}{*}{$\begin{array}{c}\mathrm{Sa} \\
\mathrm{m} \\
\mathrm{pe} \\
1\end{array}$} & $\begin{array}{l}\text { Berat } \\
(\mathrm{Kg})\end{array}$ & $\begin{array}{l}\text { Berat } \\
(\mathrm{Kg})\end{array}$ & $\begin{array}{l}\text { Berat } \\
(\mathrm{Kg})\end{array}$ & $\begin{array}{l}\text { Berat } \\
(\mathrm{Kg})\end{array}$ \\
\hline & & $\begin{array}{l}\text { Kontr } \\
\text { ol }\end{array}$ & $700^{\circ} \mathrm{C}$ & $800^{\circ} \mathrm{C}$ & $900^{\circ} \mathrm{C}$ \\
\hline \multirow{4}{*}{$\begin{array}{l}28 \\
\text { har } \\
\text { i }\end{array}$} & 1 & 12,15 & 12,45 & 12,17 & 12,1 \\
\hline & 2 & 11,79 & 12,01 & 11,98 & 12,27 \\
\hline & 3 & 11,85 & 12,06 & 12,31 & 12,41 \\
\hline & 4 & 12,31 & 12,04 & 12,15 & 12,23 \\
\hline \multicolumn{2}{|c|}{$\begin{array}{r}\text { Rata - } \\
\text { Rata }\end{array}$} & 12,02 & 12,14 & 12,15 & 12,25 \\
\hline
\end{tabular}

Sumber : Data Uji Berat Isi, 2018

Berdasarkan data pengujian berat isi beton dapat diketahui bahwa dengan melakukan penggantian sebagian semen dengan abu cangkang kerang hijau mempengaruhi berat isi beton. Penggunaan abu cangkang kerang hijau sebagai pengganti sebagian semen pada beton membuat beton mengalami penambahan berat. Beton mengalami penambahan berat isi maksimal pada suhu pembakaran $900^{\circ} \mathrm{C}$. Semakin tinggi suhu pembakaran pada cangkang kerang, semakin meningkat berat isi pada beton. Beton mengalami penambahan berat isi sebanyak $1,91 \%$ dari beton normal.

\section{Hasil Pengujian Kuat Tekan Beton}

Beton yang telah direndam dan dilakukan uji berat isi selanjutnya akan dilakukan pengujian kuat tekan. Kuat tekan beton didapatkan dari beban maksimum yg dapat diterima oleh benda uji dibagi dengan luas penampang benda uji. Hasil kuat tekan beton dapat dilihat pada Tabel 7 . 


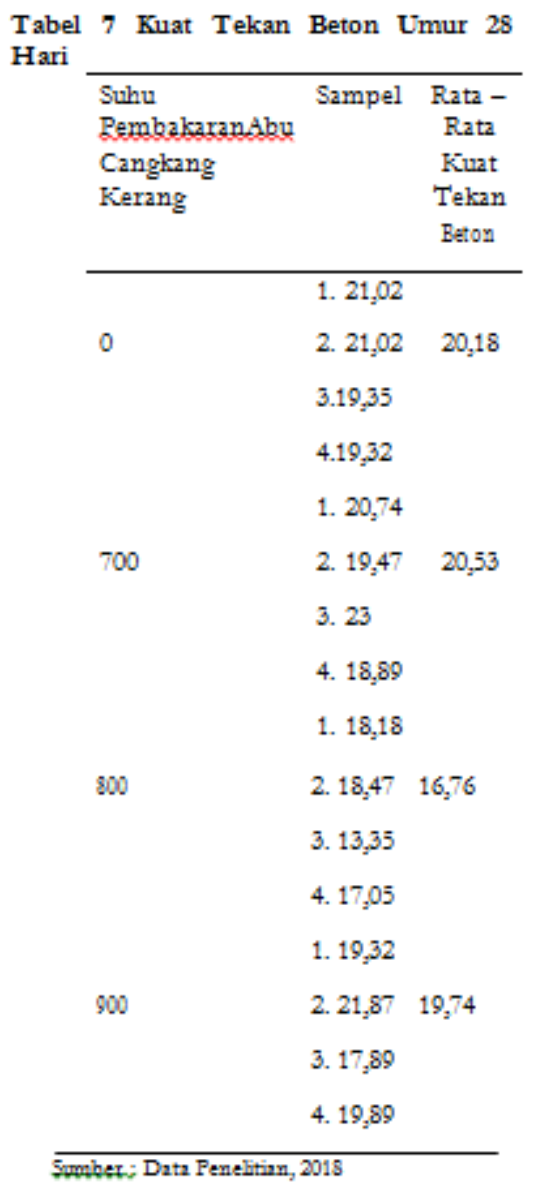

\section{Analisis Data Keseluruhan}

Hasil keseluruhan uji pada beton mutu f'c $20 \mathrm{MPa}$ dengan mengganti $10 \%$ berat semen dengan abu cangkang kerang hijau yang dibakar dengan suhu $700^{\circ} \mathrm{C}, 800^{\circ} \mathrm{C}$ dan $900^{\circ} \mathrm{C}$ dengan pengujian kuat tekan umur 28 hari.

Proses pembuatan benda uji beton menggunakan mesin mixer. Pengujian berat isi menunjukkan bahwa dengan adanya penggantian sebagian semen dengan abu cangkang kerang hijau menjadikan beton lebih berat dibandingkan dengan beton normal. Semakin tinggi suhu pembakaran, semakin berat beton yang dihasilkan. Hasil yang didapat dari pengujian kuat tekan pada beton umur 28 hari adalah meningkatnya kuat tekan beton dengan penggantian sebagian semen dengan abu cangkang kerang pada suhu pembakaran $700^{\circ} \mathrm{C}$ dibandingkan dengan beton normal.
Sedangkan, pada abu cangkang kerang dengan pembakaran suhu $800^{\circ} \mathrm{C}$ dan $900^{\circ} \mathrm{C}$ beton mengalami penurunan kuat tekan beton.

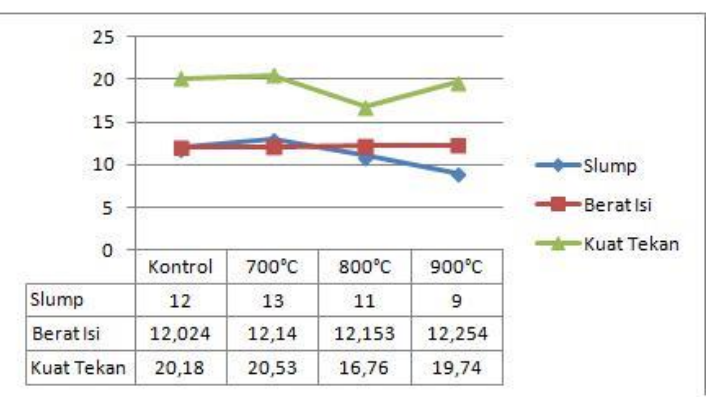

Gambar 1

Tabel 8 Perbandingan Slump, Berat Isi dan Kuat Tekan

$$
\begin{array}{lll}
\text { Beton } & \text { Nilai } & \text { Berat Kuat } \\
\text { Slump } & \text { Isi } & \text { Tekan }
\end{array}
$$

\begin{tabular}{|c|c|c|c|c|}
\hline \multicolumn{2}{|r|}{ Kontr } & 1 & 12,02 & 20 \\
\hline \multirow[t]{2}{*}{ ol } & 2 & 4 & 18 & \\
\hline & & 1 & & 20 \\
\hline \multirow{2}{*}{\multicolumn{2}{|c|}{$700^{\circ} \mathrm{C} 4$}} & & 12,1453 & \\
\hline & & 1 & 12,15 & 16 \\
\hline \multirow{2}{*}{\multicolumn{2}{|c|}{$800^{\circ} \mathrm{C} 1$}} & 3 & 76 & \\
\hline & & & 12,25 & 19, \\
\hline & $900^{\circ} \mathrm{C}$ & 94 & 74 & \\
\hline
\end{tabular}

Sumber : Data Penelitian, 2018

Kuat tekan beton optimal didapatkan pada suhu pembakaran $700^{\circ} \mathrm{C}$. Berdasarkan data yang didapat dari hasil nilai slump beton dengan suhu pembakaran $700^{\circ} \mathrm{C}$, nilai slump lebih tinggi dibandingkan dengan beton normal. Beton dengan suhu pembakaran $800^{\circ} \mathrm{C}$ dan $900^{\circ} \mathrm{C}$ memiliki nilai slump lebih rendah dibandingkan dengan beton normal. Berat isi beton dengan suhu pembakaran $700^{\circ} \mathrm{C}$ mengalami peningkatan dibandingkan dengan beton normal. Hal ini disebabkan karena berat jenis yang dimiliki oleh beton abu kerang hijau dengan pembakaran $700^{\circ} \mathrm{C}$ lebih besar dibandingkan dengan berat jenis semen. Kuat tekan beton abu cangkang kerang 
hijau dengan suhu pembakaran $700^{\circ} \mathrm{C}$ lebih tinggi jika dibandingkan dengan beton kontrol. Hal ini disebabkan karena kandungan $\mathrm{CaO}$ dan $\mathrm{Na} 2 \mathrm{O}$ pada abu cangkang kerang dengan suhu pembakaran $700^{\circ} \mathrm{C}$ lebih tinggi jika dibandingkan dengan beton dengan suhu pembakaran $800^{\circ} \mathrm{C}$ dan $900^{\circ} \mathrm{C}$.

Nilai slump beton abu cangkang kerang hijau dengan suhu pembakaran $800^{\circ} \mathrm{C}$ mengalami penurunan jika dibandingkan dengan beton normal. Hal ini dapat mempengaruhi berat isi beton. Hasil dari uji slump menunjukkan bahwa beton dengan abu cangkang kerang pembakaran suhu $800^{\circ} \mathrm{C}$ lebih padat dan memiliki kandungan air yang lebih sedikit jika dibandingkan dengan beton normal. Hal ini menyebakan sedikitnya pori pada beton sehingga meningkatkan berat isi beton. Kuat tekan beton abu cangkang kerang hijau dengan suhu pembakaran $800^{\circ} \mathrm{C}$ mengalami penurunan dibandingkan beton normal. Hal ini dapat disebabkan karena menurunnya kadar $\mathrm{CaO}$ yang dimiliki oleh abu cangkang kerang dengan suhu pembakaran $800^{\circ} \mathrm{C}$. Selain itu, sedikitnya senyawa $\mathrm{Na} 2 \mathrm{O}$ dan banyaknya unsur $\mathrm{C}$ pada abu cangkang kerang hijau dengan suhu pembakaran $800^{\circ} \mathrm{C}$ membuat rendahnya kuat tekan beton.

Nilai slump beton abu cangkang kerang hijau dengan suhu pembakaran $900^{\circ} \mathrm{C}$ lebih rendah jika dibandingkan dengan beton normal. Berat isi beton abu cangkang kerang hijau dengan suhu pembakaran $900^{\circ} \mathrm{C}$ lebih tinggi dibandingkan dengan beton normal disebabkan karena nilai slump yang lebih rendah. Hal ini terjadi karena sedikitnya air yang terkandung sehingga beton menjadi lebih padat dan lebih berat. Kuat tekan beton abu cangkang kerang pembakaran suhu $900^{\circ} \mathrm{C}$ lebih rendah dibandingkan dengan beton normal disebabkan oleh menurunnya kadar $\mathrm{CaO}$ dan $\mathrm{Na} 2 \mathrm{O}$.

Keterbatasan Masalah Dalam penelitian yang dilakukan terdapat beberapa keterbatasan, di antaranya:
1. Oven yang digunakan dalam proses pembakaran cangkang kerang hijau berbahan bakar gas, sehingga butuh waktu lama untuk mencapai suhu yang ditentukan.

2. Pada proses pembakaran cangkang kerang suhu $900^{\circ} \mathrm{C}$ terjadi pergantian gas sehingga mengakibatkan penurunan suhu. Hal ini berdampak pada kandungan kimia pada abu cangkang kerang hijau yang akan diteliti.

3. Pengovenan cangkang kerang hijau serta pengujian kandungan kimia abu cangkang kerang hijau hanya dilakukan sekali sehingga tidak dapat diambil nilai rata-rata.

4. Perawatan benda uji dengan cara direndam dilakukan selama 25 hari karena terbentur hari sabtu dan minggu, sdan kuat tekan beton dilakukan pada umur 28 hari.

\section{KESIMPULAN}

Berdasarkan hasil kesimpulan serta pembahasan masalah, sesuai dengan perumusan masalah "Apakah penggunaan abu cangkang kerang hasil pembakaran dengan variasi suhu $700^{\circ} \mathrm{C}, 800^{\circ} \mathrm{C}$ dan $900^{\circ} \mathrm{C}$ sebagai pengganti sebagian semen pada pembuatan beton akan mempengaruhi kuat tekan yang dihasilkan?", maka dapat disimpulkan sebagai berikut:

1. Berdasarkan Penggantian $10 \%$ berat semen dengan abu cangkang kerang hijau yang dibakar dengan suhu $700^{\circ} \mathrm{C}, 800^{\circ} \mathrm{C}$ dan $900^{\circ} \mathrm{C}$ pada umur 28 hari menghasilkan kuat tekan maksimum pada suhu pembakaran $700^{\circ} \mathrm{C}$. Kuat tekan beton dengan abu cangkang kerang suhu pembakaran $700^{\circ} \mathrm{C}, \quad 800^{\circ} \mathrm{C}$ dan $900^{\circ} \mathrm{C}$ berturut - turut adalah 20,53 ; 16,76 dan 19,74. Sedangkan kuat tekan beton normal adalah 20,18. Kuat tekan optimum terdapat pada penggunaan abu cangkang kerang dengan suhu pembakaran $700^{\circ} \mathrm{C}$. 
2. Suhu pembakaran optimum dalam menguraikan unsur kimia yang terdapat pada cangkang kerang hijau adalah suhu $700^{\circ} \mathrm{C}$.

3. Penggunaan abu cangkang kerang hijau sebagai pengganti $10 \%$ berat semen menjadikan beton lebih berat dibandingkan dengan beton normal. Semakin tinggi suhu pembakaran, maka semakin bertambah berat isi beton.

\section{SARAN}

Untuk menghasilkan penelitian yang lebih baik, maka disarankan:

1. Untuk penelitian selanjutnya dapat dilakukan variasi terhadap waktu pembakaran agar dapat dilihat waktu yang tepat agar senyawa kimia yang terdapat di dalam cangkang kerang hijau dapat keluar secara optimal.

2. Perlu dilakukan adanya penelitian lanjutan dengan suhu pembakaran antara $650^{\circ} \mathrm{C}, 700^{\circ} \mathrm{C}$ dan $750^{\circ} \mathrm{C}$ untuk mencari suhu pembakaran yang dapat mengeluarkan kandungan kimia dalam cangkang kerang hijau secara optimum.

3. Memastikan sumber bahan bakar oven sebelum melakukan proses pembakaran cangkang kerang agar tidak terjadi pengisian ulang bahan bakar di saat percobaan sedang berlangsung sehingga menimbulkan penurunan suhu dan perlakuan yang berbeda terhadap variabel lainnya.

4. Variasi tempat asal kerang hijau, karena kerang hijau yang berasal dari daerah berbeda memiliki berat jenis serta diperlukan adanya perlakuan yang berbeda.

\section{DAFTAR PUSTAKA}

Abrori, Ahmad Alfan. (2015). Pemanfaatan Abu Kulit Kerang Hijau Sebagai Pengganti Sebagian Semen Pada Pembuatan Beton. [Skripsi]. Jakarta: Universitas Negeri Jakarta.

Arif, A. R., dkk. 2013, Isolasi Kitin dari Limbah Udang Putih (Penaeus merguiensis) Secara Enzimatis. Seminar Nasional Kimia Peran Sain dan Teknologi Dalam Mendukung Ketahanan Pangan dan Energi Nasional.

Asto, E. S., dkk. 2015, Pengaruh pH dan Lama Kontak pada Adsorpsi Ion Logam $\mathrm{Cu} 2+$ Menggunakan Kitin Terikat Silang Glutaraldehid. Kimia Student Journal, 1(1): 647-653.

Cappenberg, H.A.W. (2008). Beberapa Aspek Biologi Kerang Laut. [Jurnal]. Oseana, 33: 33-40. Jurnal Pendidikan Teknik Sipil

Martati, E., dkk. 2012, Isolasi dari Cangkang Rajungan (Portunus pelagicus) Kajian Suhu dan Waktu Proses Deproteinasi. J. Tek. Pert. 3(2): 129-137.

Maulana, Eki. (2014). Penggunaan Abu Kulit Kerang Hijau Sebagai Substitusi Sebagian Volume Semen Pada Batako Berlubang. [Skripsi]. Jakarta: Universitas Negeri Jakarta.

Seperti Tanggul. https://www.merdeka.com/jakarta/sa mpah-kulit-kerang-numpuk-dimuaracakung-drain-seperti tanggul.html. Diakses 19 Mei 2018.

Sutanto, Dharmawan. (2014). Sampah Kulit Kerang Numpuk di Muara Cakung Drain

Syafpoetri, Nelvia., Olivia, M., \& Darmayanti, L. (2013). Pemanfaatan Abu Kulit Kerang (Andara Grandis) Untuk Pembuatan 
Ekosemen. [Jurnal]. Pekanbaru:

Universitas Riau.

Ummah, Sayidatul., Prasetyo, Anton., \& Baroroh, Himmatul. (2010). Kajian Penambahan Abu Sekam Padi Dari Berbagai Suhu Pengabuan Terhadap Plastisitas Kaolin. [Jurnal]. Malang: Universitas Islam Negeri Maulana Malik Ibrahim. 